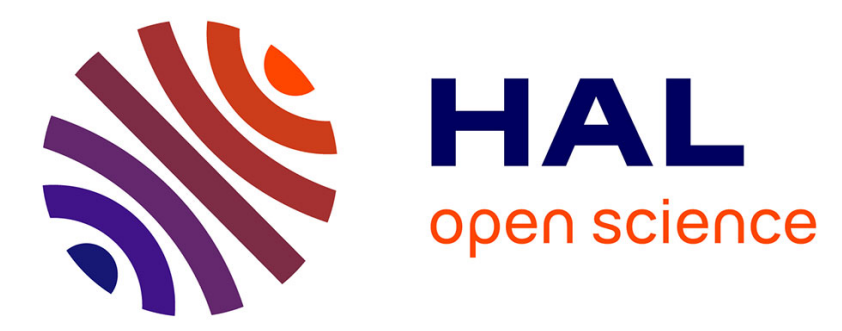

\title{
Are risk preferences consistent across elicitation procedures? A field experiment in Congo Basin countries
}

Marielle Brunette, Jonas Ngouhouo-Poufoun

\section{- To cite this version:}

Marielle Brunette, Jonas Ngouhouo-Poufoun. Are risk preferences consistent across elicitation procedures? A field experiment in Congo Basin countries. 2021. hal-03132834

\section{HAL Id: hal-03132834 \\ https://hal.inrae.fr/hal-03132834}

Preprint submitted on 5 Feb 2021

HAL is a multi-disciplinary open access archive for the deposit and dissemination of scientific research documents, whether they are published or not. The documents may come from teaching and research institutions in France or abroad, or from public or private research centers.
L'archive ouverte pluridisciplinaire HAL, est destinée au dépôt et à la diffusion de documents scientifiques de niveau recherche, publiés ou non, émanant des établissements d'enseignement et de recherche français ou étrangers, des laboratoires publics ou privés.

\section{(c)(1)}

Distributed under a Creative Commons Attribution| 4.0 International License 


\title{
«Are risk preferences stable? A field experiment in Congo Basin countries»
}

\author{
$\underline{\text { Auteurs }}$ \\ Marielle Brunette, Jonas Ngouhouo-Poufoun
}

Document de Travail n² $2019-18$

Bureau d'Économie

Théorique et Appliquée

BETA

www.beta-umr7522.fr

ybeta_economics

Contact :

jaoulgrammare@beta-cnrs.unistra.fr 


\title{
Are risk preferences stable? A field experiment in Congo Basin countries
}

\author{
Marielle Brunette*and Jonas Ngouhouo-Poufoun ${ }^{\dagger}$
}

May 15, 2019

\begin{abstract}
We compare individual risk preferences elicited through a classic Ordered Lottery Selection (OLS) procedure with five gambles, and an extended procedure composed of nine gambles. The research question is about the stability of the risk preferences across these two elicitation variants. We implemented a field experiment with 1002 rural households in the Congo Basin from December 2013 to July 2014. We show that $1 / 3$ of the sample is extremely risk averse regardless of the procedure. We found inconsistencies in risk preferences elicited across procedures. Indeed, $45.71 \%$ are characterized by instability of preferences, either weak $(34.53 \%)$ or strong $(11.18 \%) ; 42.81 \%$ of the sample exhibits stable preferences and the remaining $11.48 \%$ of the sample - initially risk neutral in the classic procedure - is classified as risk loving in the extended procedure. Undereducation can be seen as the main driver of the strong instability since the incremental change brought about by the attainment of secondary school on the likelihood to remain stable is ten times greater than the other considered drivers.
\end{abstract}

Keywords: field experiment, risk aversion, ordered lottery selection, preferences, farmers.

JEL codes: C93, D81.

* Corresponding author: Université de Lorraine, Université de Strasbourg, AgroParisTech, CNRS, INRA, BETA, 54000, Nancy, France. Phone: +33 (0)3 833968 56. marielle.brunette@inra.fr; Associate researcher at the Climate Economic Chair, Paris, France.

${ }^{\dagger}$ Université de Lorraine, Université de Strasbourg, AgroParisTech, CNRS, INRA, BETA, Nancy, France; Center for International Forestry Research, Jl. CIFOR, Situ Gede, Bogor (Barat) 16115, Indonesia. 


\section{Introduction}

Risk preferences are known to be an important determinant of most of the decisions regarding risk. As a consequence, experimental economics has developed procedures to quantify these risk preferences. The two most common procedures are the Multiple Price List (MPL) method, popularized by Holt and Laury (2002), and the Ordered Lottery Selection (OLS) method, proposed by Binswanger (1980) and popularized by Eckel and Grossman (2008). Other methods also appear in the literature such as the certainty equivalent approach, the Becker-DeGroot-Marschak auction or the method proposed by Gneezy and Potters (1997).

These methods are largely used in economics to measure risk preferences, and some studies compare the results obtained with different methods. For example, Dave et al. (2010) showed that risk aversion is, on average, higher with a MPL procedure than with an OLS procedure. Reynaud and Couture (2012) found the opposite result. Anderson and Mellor (2009) compared risk preferences measurement between an experiment and a survey. They found that only the individual's risk preferences classification from inheritance-based gambles are in-line with experimental measurements. Other comparisons appeared for elicitation techniques (Berg et al. (2005), Deck et al. (2008), Chuang and Schechter (2015)) but with an unanimous conclusion: elicited risk preferences are proceduredependent, and risk preferences tend to be more stable when the elicitation procedures are similar to one another (Choi et al. (2007), Chuang and Schechter (2015)).

In this paper, rather than comparing two different elicitation techniques, we focus on two variants of the same procedure. Contrary to the other existing procedures, classic OLS procedure as proposed by Eckel and Grossman (2008) does not allow the precise identification of risk loving preferences. Indeed, risk neutrality and risk loving are expressed in the same last gamble choice, and are then impossible to disentangle. In this context, several interesting questions emerge: How much individuals selecting this last gamble are risk loving and at which degree ? Are individual's preferences towards risk stable across elicitation procedures? If not, are there different degrees of instability ? What are the driving factors of the instability?

To address these questions, we conducted a field experiment in which we elicited risk preferences through a classic OLS procedure composed of five gambles and an extended OLS procedure composed of nine gambles, and allowed the elicitation of different degrees of risk loving compared to the classic OLS. This experiment contributes to the debate on the stability of individual prefer- 
ences across elicitation procedures. The experiment is implemented on 1002 rural households in the Congo Basin. Rural households in developing countries are a common sample for elicitation of risk preferences via the OLS procedure (Binswanger (1980), Chuang and Schechter (2015)).

We categorized the sample function of the (in)stability of the head of households' risk preferences between the two OLS variants. Specifically, we showed that $42.81 \%$ of the sample belongs to the category "stable preferences", $34.53 \%$ have a "weak instability", while $11.18 \%$ have a "strong instability". The remaining of the sample were households who are fundamentally risk loving and were constrained by the classic elicitation procedure (11.48\%). We then considered household assets and socioeconomic characteristics to estimate a statistical model to characterize instability and derive its potential drivers.

The paper is organized as follows. We first describe the experimental design and the two elicitation variants. Second, we present the results focusing on the preferences of the households towards risk and the stability (or not) of these preferences. Third, we analyze the potential drivers of the instability. Finally, we provide a discussion and a conclusion.

\section{Experimental design and procedures}

The experiment was realized in the field on a sample of 1002 rural households in the Congo basin from December 2013 to July 2014. The experiment took place in the Dja-Odzala-Minkébé transboundary conservation landscape (Tridom), which spans Cameroon, Gabon and Congo.

The OLS experiment was realized during a face-to-face survey as part of a larger questionnaire aiming at assessing "rural households livelihoods system, deforestation and biodiversity conservation". A short summary of the questionnaire is provided in Appendix A, while the interested reader is referred to Poufoun et al. (2016) for a complete overview.

The experiment was purely hypothetical, in the sense that no financial incentives were provided to the subjects. This choice was driven by several reasons. First, Camerer and Hogarth (1999) and Beattie and Loomes (1997) showed that, since questions are related to simple lottery choices, monetary incentives do not significantly affect decision-making. In the same vein, some papers show no difference between decisions made with hypothetical or real payoffs (Battalio et al. (1990); Wik et al. (2004)). Finally, Chuang and Schechter (2015) found no difference in the stability of hypothetical versus incentivized measure of risk preferences. However, to facilitate the understanding, 
matchboxes were used to represent the lottery choices (probabilities and payoffs), and households kept the box at the end of the experiment.

We elicited individual's risk preferences through two OLS procedures. We used a within-subjects design so that each of the 1002 household's head performed both procedures. The first one, presented in Table 1, is a classic OLS procedure as proposed by Eckel and Grossman (2008) in which an individual must choose among five gambles the one s/he accepts to play for. Each gamble consists of two payoffs, each of which is obtained at the same probability of $50 \%$. The choice of a gamble allows one to infer an interval for the relative risk aversion coefficient, supposing that subjects have a constant relative risk aversion utility function of the form $U=x^{(1-r)} /(1-r)$, where $r$ is the relative risk aversion coefficient. This specification implies risk neutrality for $r=0$ and risk aversion for $r>0$.

In this procedure, gambles 1 to 4 correspond to different degrees of risk aversion. The individual who choose Gamble 5 may be risk neutral or risk loving. The procedure does not allow one to disentangle the latter two categories of preferences towards risk.

Table 1: Classic OLS procedure with 5 gambles

\begin{tabular}{c|c|c|c|c}
\hline \hline Choice 50/50 gamble & Payoff 1 & Payoff 2 & Coef. of RRA ranges & Risk profile \\
\hline Gamble 1 & 4 & 4 & $\mathrm{r}>2$ & Extremely risk averse \\
Gamble 2 & 3 & 6 & $0.67<\mathrm{r}<2$ & Highly risk averse \\
Gamble 3 & 2 & 8 & $0.38<\mathrm{r}<0.67$ & Very risk averse \\
Gamble 4 & 1 & 10 & $0.20<\mathrm{r}<0.38$ & Slightly risk averse \\
Gamble 5 & 0 & 12 & $\mathrm{r}<0.20$ & Risk neutral/Risk loving \\
\hline
\end{tabular}

Reynaud and Couture (2012) proposed an extended OLS procedure composed of nine gambles to allow for a finer characterization of risk loving preferences. Table 2 presents the procedure. The gambles 7, 8 or 9 correspond to different degrees of risk loving, from slightly to very risk loving. In the extended procedure, there are five categories for risk aversion, while only four are represented in the classic one. We can observe that "Risk averse" (choice of Gamble 4) and "Very risk averse" (choice of Gamble 3) in the extended procedure are gathered in "Very risk averse" gamble in the classic procedure. The households are always given Table 1 first, and then Table 2 . 
Table 2: Extended OLS procedure with 9 gambles

\begin{tabular}{c|c|c|c|c}
\hline \hline Choice 50/50 gamble & Payoff 1 & Payoff 2 & Coef. of RRA ranges & Risk profile \\
\hline Gamble 1 & 100 & 100 & $\mathrm{r}>1.37$ & Extremely risk averse \\
Gamble 2 & 80 & 128 & $0.68<\mathrm{r}<1.37$ & Highly risk averse \\
Gamble 3 & 60 & 160 & $0.44<\mathrm{r}<0.68$ & Very risk averse \\
Gamble 4 & 40 & 195 & $0.4<\mathrm{r}<0.44$ & Risk averse \\
Gamble 5 & 30 & 215 & $0.15<\mathrm{r}<0.4$ & Slightly risk averse \\
Gamble 6 & 20 & 229 & $-0.13<\mathrm{r}<0.15$ & Risk neutral \\
Gamble 7 & 18 & 232 & $-0.47<\mathrm{r}<-0.13$ & Slightly risk loving \\
Gamble 8 & 10 & 234 & $-0.93<\mathrm{r}<-0.47$ & Risk loving \\
Gamble 9 & 3 & 235 & $\mathrm{r}<-0.93$ & Very risk loving \\
\hline
\end{tabular}

Note that in the classic OLS procedure, the initial payoffs proposed in Eckel and Grossman (2008) are divided by four, while in the extended OLS procedure, the initial payoffs are multiplied by 2.5 (Reynaud and Couture, 2012). As a result, the implied ranges for the coefficient of relative risk aversion are not modified.

Consequently, by comparing preferences elicited in classic procedure and the ones elicited through the extended one, we capture both the effect of the level of the payoffs and the effect of increasing the number of possible gambles. Concerning the effect of the payoff, Holt and Laury (2002) and Reynaud and Couture (2012) found that individual's preferences are largely unaffected when hypothetical payoffs are scaled up. Concerning the effect of the increasing number of possible gambles, we expect that the average risk aversion reduces. Indeed, in the extended procedure some gamble choices correspond to negative risk aversion coefficients, so that, on average, the risk aversion of the whole sample should decrease. However, the question remains if those who are risk loving with the extended procedure are only among those who selected Gamble 5 in the classic OLS procedure or if some risk averse individuals reversed their preferences.

\section{Risk preferences and the stability: Analysis and results}

In this section, we present the results of our elicitation of household risk preferences and, based on these results, we propose a categorization of households with regard to the stability (or not) of their preferences towards risk. 


\subsection{Individual's risk preferences elicitation}

Table 3 presents the results of the experiment where columns are the five gambles of the classic procedure, and rows the nine gambles of the extended procedure.

Table 3 shows that in the classic procedure, 163 individuals are classified as risk neutral/risk loving (choice of Gamble 5) while the 839 others are risk averse (choice of gamble 1 to 4 ). In the extended procedure, 83 individuals choose Gamble 6 (i.e. $8.28 \%$ of the sample), and are therefore risk neutral, 692 chose gambles 1 to 5 (i.e. $69.07 \%$ of the sample) and are risk averse. Finally, 227 individuals choose gambles 7 to 9 (i.e. $22.65 \%$ of the sample) and are characterized as risk loving, which is approximately $1 / 4$ of the sample.

Table 3: Cross results of the classic and extended procedures

\begin{tabular}{|c|c|c|c|c|c|c|c|}
\hline & & \multicolumn{6}{|c|}{ Classic procedure } \\
\hline & & Gamble 1 & Gamble 2 & Gamble 3 & Gamble 4 & Gamble 5 & Total \\
\hline \multirow{10}{*}{ 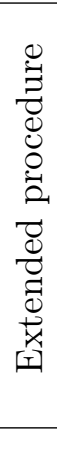 } & Gamble 1 & 270 & 21 & 18 & 5 & $\overline{4}$ & 318 \\
\hline & Gamble 2 & 31 & 63 & 18 & 5 & 11 & 128 \\
\hline & Gamble 3 & 13 & 30 & 24 & 9 & 5 & 81 \\
\hline & Gamble 4 & 6 & 33 & 22 & 10 & 8 & 79 \\
\hline & Gamble 5 & 6 & 23 & 37 & 9 & 11 & 86 \\
\hline & Gamble 6 & 5 & 15 & 34 & 20 & 9 & 83 \\
\hline & Gamble 7 & 2 & 5 & 13 & 18 & 10 & 48 \\
\hline & Gamble 8 & 2 & 5 & 7 & 20 & 13 & 47 \\
\hline & Gamble 9 & 6 & 14 & 12 & 8 & 92 & 132 \\
\hline & Total & 341 & 209 & 185 & 104 & 163 & 1002 \\
\hline
\end{tabular}

Table 3 allows the observation of high selections of extreme preferences towards risk. For both procedures, the highest frequency is for extreme risk aversion, i.e. the choice of Gamble 1. Indeed, more than $30 \%$ of the sample was revealed to be extremely risk averse. In this sense, the two procedures are consistent one with another, at least for extremely risk-averse individuals. This result comes from the fact that the first gamble is not risky, in the sense that the payoff is certain. Individuals may be sensitive to this certainty, which explains the high proportion of the sample that chose Gamble 1 in the two procedures. This idea is confirmed by follow-up questions at the end of the experiment where subjects may justify their choices. Those selecting Gamble 1 said "I don't like to play", "I don't want to take risk", "I'm prudent", etc. A high frequency is also observe for extreme risk loving in the extended procedure, i.e. the choice of Gamble 9. Of the 227 individuals who chose gamble 7 to $9,58.15 \%$ selected Gamble 9 , and are therefore very risk loving. This result is similar 
to that of Reynaud and Couture (2012), in the sense that $21 \%$ of their sample was characterized as risk loving, with a more pronounced concentration in the extreme. Indeed, in their experiment risk lovers only selected Gamble 9.

Using the center of the ranges for the relative risk aversion coefficient (Table 1 and Table 2), we can compute an average risk aversion coefficient ${ }^{1}$. This average coefficient is 1.025 for the classic OLS procedure and 0.608 for the extended OLS procedure. A Student's t-test for mean comparison reveals that the average coefficients are statistically different from each other at the 0.01\% level. Arrow (1971) suggested that individuals' coefficients of relative risk aversion should be approximately 1. Kydland and Prescott (1982) found coefficients of relative risk aversion in the range of 0 to 2 . However, the coefficient elicited through the extended procedure is closer to the estimates obtained in previous studies: 0.71 for Chinese farmers (Liu (2013)), around 0.8 for French farmers (Bocquého et al. (2014); Reynaud and Couture (2012); Bougherara et al. (2017)) and 0.69 for farmers in Burkina Faso (Cotty et al. (2014)).

Moreover, the Spearman correlation coefficient allows for the comparison of the individuals' choice across procedures. We observed a positive and significant correlation $(\rho=0.69)$ of risk preferences between both the procedures. This result is in accordance with the main finding in the literature. Indeed, Deck et al. (2010) and Reynaud and Couture (2012) found a positive and significant correlation between the risk preferences elicited through Holt and Laury's task and Eckel and Grossman's task ( $\rho=0.21$ and $\rho=0.4$, respectively). Our correlation is stronger, probably because we compare two variants of the same procedure.

To conclude, we have two possible effects at work: a payoff effect (expected to have no effect on risk preferences) and an effect linked to the increasing number of possible gambles (expected to be negative for risk aversion). Our results revealed that in the extended OLS procedure, as compared to the classic one, a lower proportion of the sample is risk averse and the average risk aversion coefficient is lower, suggesting that the payoff effect is non-existent in this experiment.

\subsection{Stability (or not) of the preferences towards risk: A categorization}

Table 3 allows us to categorize households in regard to the stability of their preferences towards risk. These four categories are represented through different shades of gray in Table 3.

\footnotetext{
${ }^{1}$ We assume 2.5 and -2 as class midpoints for extreme ranges in the extended procedure and 2.5 and 0 in the classic one.
} 
The first category of households includes individuals with "stable preferences" towards risk (white cells in Table 3). Reynaud and Couture (2012) consider that preferences are stable across tasks if CRRA ranges are the same between procedures. In our case, the CRRA ranges are not identical and sometimes they overlap. As a consequence, we first consider the choice of the individual in the classic procedure to have her/his CRRA range, and then, we compare this to the gamble choice in the extended procedure, in terms of the risk aversion coefficient. For example, if an individual choses Gamble 1 in the classic procedure, this means that her/his relative risk aversion coefficient is higher than 2 and it is compatible only with the choice of Gamble 1 in the extended procedure. As a consequence, we assume that an individual who chooses Gamble 1 in the classic procedure has stable preferences only if $\mathrm{s} /$ he chooses Gamble 1 in the extended procedure. Another example of stable preferences is an individual choosing Gamble 2 in the classic procedure $(0.67<r<2)$ and gambles 1 or 2 in the extended one. The "stable preferences" category makes up $42.81 \%$ of the sample (429 households).

The second category of households is made up of individuals with a "strong instability" of preferences towards risk (light gray cells in Table 3). This category includes $49.43 \%$ of risk loving in the extended procedure who expressed risk aversion in the classic procedure. In other words, this category represents individuals who switched from risk aversion in the classic procedure to risk loving in the extended one, i.e. who have reversed their preferences. This category represents 112 households, or $11.18 \%$ of the overall sample.

The third category is associated with households who have a "weak instability" of preferences towards risk (medium gray cells in Table 3). It comprises individuals who deviated in the extended procedure from their CRRA range estimated in the classic procedure. For example, if an individual chooses the Gamble 2 in the extended procedure $(0.67<r<2)$, s/he is characterized by weak instability if $\mathrm{s} /$ he chooses gambles $3,4,5$ or 6 in the extended procedure. The preferences of 346 households are characterized by "weak instability" (i.e. $34.53 \%$ ).

The remaining 115 individuals represent the fourth category that we qualify as "false neutral" (dark gray cells in Table 3) in the sense that they choose Gamble 5 in the classic procedure but stated to be risk loving in the extended one. It seems that most of the individuals choosing Gamble 5 in the classic OLS procedure were fundamentally risk loving. The choice of Gamble 5 in the classic procedure reveals that the other options do not fit them, and as a consequence that they are not risk averse. In follow-up questions, we asked subjects to explain their choice. Individuals choosing 
Gamble 5 in the classic procedure and gambles 7, 8 or 9 in the extended ones indicated the following reasons among others: "I like to take risk" or "I'm attracted by potential big gains".

Final important result is that the lower the risk aversion in the classic procedure, the higher the chance to be risk loving in the extended procedure. Indeed, we observe that among individuals who choose Gamble 1 in the classic procedure, 10 reversed their preferences, switching from risk aversion to risk loving, in the extended procedure. The number of individuals who reversed their preferences is 24 when choosing Gamble 2 in the classic procedure, 32 when choosing Gamble 3, and 46 when choosing Gamble 4.

\section{Drivers of risk preferences instability}

The experiment represents a part of a larger survey. In this section, we used variables coming from a questionnaire submitted to the households during the larger survey to try to explain (in)stability. Section 4.1 describes the descriptive statistics associated with these variables whereas Section 4.2 presents the econometric results of a probit analysis designed to identify the potential drivers of instability.

\subsection{Some descriptive statistics of the sample}

Table 4 reports the descriptive statistics of the sample. In the Tridom landscape, the humanelephant-conflict (HEC) is at the heart of the discussion. This specificity is taken into account through three variables: whether heads of households faced such conflicts or not, the elephant density in the neighbourhood and the damage from HEC to crops. We can observe that HEC damages livelihoods of about $27 \%$ of households in the study area, generates damages to crop for $90.12 \mathrm{CFA}$ 1000/years on average, and that, on average, 0.93 elephants/hectare are present in the household neighbourhoods. Our intuition is that households confronted to HEC are familiar with the notion of risk and risk management, in which case these three variables likely impact the stability of their risk preferences. In the same vein, the literature shows that exogenous shocks such as natural disasters or violent conflict affect risk preferences (Schildberg-Horisch (2018)).

We consider three types of assets: land holding in hectares as an indicator of natural assets, money transfer and access to credit as indicators of financial assets, and membership of a community group 
of interest ${ }^{2}$ as an indicator of social assets. We expect households with higher assets being more stable.

We expect educated households to be prone to stability. We then ask whether the respondent reached secondary school (the answer is "yes" for $56 \%$ of the sample). Indeed, following Choi et al. (2007), less educated respondents play less consistently in risk preferences game.

We consider the number of years settled in villages (seniority) with the idea that households who settled long ago may be more prone to stability. The statistics reveal that households resided in a village for an average of 27 years.

Table 4: Descriptive statistics $(\mathrm{N}=1002)$

\begin{tabular}{lllll}
\hline Variables & Mean & Std. Dev. & Min & Max \\
\hline Continuous & & & & \\
\hline Elephant density (number/hectare) & 0.93 & 0.84 & 0.23 & 2.78 \\
Damage from HEC (*CFA 1000/years) & 90.12 & 209 & 0 & 1200 \\
Land holding (in hectars) & 4.48 & 5.30 & 0 & 56.25 \\
Access to credit (*CFA 1000/years) & 46.81 & 351.75 & 0 & 9000.00 \\
Money transfer (*FA 1000/years) & 58.23 & 191.13 & 0 & 3000.00 \\
Baka employment & 1.85 & 2.94 & 0 & 12 \\
Seniority (in years) & 26.88 & 20.75 & 0 & 90.00 \\
Household size & 6.45 & 4.02 & 0 & 20.00 \\
Age & 48.40 & 14.61 & 16 & 90.00 \\
\hline Dummy & & & & \\
\hline Reach secondary school & 0.56 & 0.49 & 0 & 1 \\
Reliance on forest & 0.71 & 0.45 & 0 & 1 \\
Community group (Yes =1) & 0.28 & 0.45 & 0 & 1 \\
Human-elephant-conflict (Yes =1) & 0.27 & 0.44 & 0 & 1 \\
Gender (Male = 1) & 0.76 & 0.42 & 0 & 1 \\
Marital status (Married =1) & 0.72 & 0.45 & 0 & 1 \\
\hline
\end{tabular}

We include the variable "Baka employment" that is a very low cost-labor force that households may use. In the sample, on average, 1.85 Baka autochtonous per household are employed temporary to realize works in the fields.

Finally, we ask respondents to indicate if they rely on forest products, which is the case for $71 \%$ of the sample.

Among socioeconomic features as possible characteristics of instability, we consider marital status

\footnotetext{
${ }^{2}$ The purpose of a common initiative group of interest is to promote the economic and social development of members through the development of income-generating activities and to overcome the constraints faced by individual small-scale farmers (Biénabe and Sautier, 2005).
} 
(72\% of the sample are married), age (an average of 48.40 years), household size (average of 6.45 individuals per household) and gender (sample composed of $76 \%$ of male). In particular, we test for gender-specific differences in the stability of risk preferences as proposed by Filippin and Crosetto (2016).

\subsection{Factors of risk preferences instability across elicitation procedures}

The fundamental difference between both variants of OLS procedure considered in this paper resides in the risk loving categories of the extended procedure, giving the opportunity to those classified in the neutral category of the classic OLS procedure to express their risk loving preferences. According to Section 3 above, 115 of the 227 risk lovers identified in the extended procedure hail from the neutral category in the classic OLS procedure and are characterized as "false neutral". The remaining 112 risk lovers hail from the risk averse category in the classic OLS procedure. They reversed their risk preferences and are characterized with "strong instability". In this subsection, we conduct a binary probit analysis to compare the variables associated to households characterized with "strong instability" to those who are "false neutral". As a consequence, comparing these two sub-samples allows identifying potential drivers of the strong instability. Results of the probit regression are presented in Table 5.

Table 5: Results of the binary probit regression (instability $=1$ )

\begin{tabular}{lrrrl}
\hline & Estimate & Std. Err. & Marg. effects & Sign. \\
\hline Land holding & -0.0562 & 0.0597 & -0.0039 & \\
Financial asset & -0.0156 & 0.0086 & -0.0011 & $*$ \\
Baka employment & -0.2153 & 0.1059 & -0.0151 & $* *$ \\
Reliance on forest & 6.1532 & 331.597 & 0.4306 & \\
Community group & 0.9398 & 0.4753 & 0.0658 & $* *$ \\
Seniority & 0.0225 & 0.0133 & 0.0016 & $*$ \\
Damage from HEC & 0.0167 & 0.0089 & 0.0012 & $*$ \\
Reach secondary school & -1.6216 & 0.467 & -0.1135 & $* * *$ \\
Gender & 0.3523 & 0.5289 & 0.0247 & \\
Age & -0.0749 & 0.0223 & -0.0052 & $* * *$ \\
(Intercept) & -4.0114 & 331.5981 & & \\
\hline Log Lik $(\mathrm{df}=11)$ & -29.191 & & & \\
AIC & 80.383 & & & \\
\hline \multicolumn{5}{c}{ Significance level $(\mathrm{p}):{ }^{*}=10 \%, * *=5 \%, * *=1 \%}$. \\
\end{tabular}

We observe that individuals with higher financial assets, employ Baka autochtonous, reached sec- 
ondary school, as well as elder individuals are more likely to express stable risk preferences. Indeed, individuals with 1000 more CFA are associated with 0.11 less percentage point on their likelihood to express unstable risk preferences. Individuals employing one more Baka community members are 1.51 percentage point less prone to express unstable risk preferences. Older respondents and those who reached secondary school, are 0.52 and 11.35 percentage points less prone to express unstable risk preferences respectively.

Conversely, belonging to a community group of interest, experiencing greater damages from HEC, and residence time in the village tend to favor instability. An increase of 1000 CFA of crop damage by elephants implies 0.12 more percentage points to the probability to express unstable risk preferences. An additional year spent in the village after settlement implies 0.16 more percentage points to the likelihood to express instability. Finally, respondents who are members of a community group of interest are $6.58 \%$ more likely to express unstable risk preferences, a finding which is opposite to our expectations.

To conclude, it appears that the marginal effect of education on the likelihood to remain stable is 11.35 percentage points, an amount about ten times greater than other statistically significant drivers. Education improves the understanding of the experimental game and allows a better appraisal of the different gambles, implying more stability in risk preferences. Our result is in accordance with the one of Choi et al. (2007).

\section{Discussion}

The literature has previously identified potential factors explaining instability of risk preferences (Reynaud and Couture (2012)).

The first potential driver of instability is the context-dependency of the risk preferences (Deck et al. (2008), Barseghyan et al. (2011)). For example, Barseghyan et al. (2011) found that survey participants are characterized by higher risk aversion when the choice is about home insurance as compared to car insurance. However, this potential explanation is not relevant in our experiment because the two elicitation variants are realized exactly in the same framework.

Second, Anderson and Mellor (2009) and Dave et al. (2010) stipulated that differences in cognitive ability of subjects, and task complexity may be relevant drivers. Our result is in line with the first part of this assertion, in the sense that education has a positive and significant impact on 
stability. This result is in accordance with Dave et al. (2010), who observed that Holt and Laury's task leads to more inconsistent choices than Eckel and Grossman's task among individuals with lower mathematical skills. Concerning task complexity, the extended procedure may be considered as more complex since the choice of a gamble is more complicated with nine as opposed to five gambles. However, as Reynaud and Couture (2012), we obtain a lower risk aversion with the most complex task.

Third, Choi et al. (2007) and Chuang and Schechter (2015) observed that instability increases when the elicitation procedures are too different. In our experiment, the two procedures are two OLS variants. We can thus think that this driver is not relevant in our case. Moreover, this similarity between the two elicitation procedures may explain why we have a quite high level of stability in our sample (42.81\%) and a high correlation coefficient between the individuals' choices in the two procedures $(\rho=0.69)$.

A last potential driver, puts forward by Bocquého et al. (2014), is the misspecification of individual preferences. The two procedures that we tested assume an expected utility framework. However, household's head may behave accordingly to other types of preferences, in particular prospect theory (see Reynaud and Couture (2012), Bocquého et al. (2014) and Bougherara et al. (2017) for French farmers and Harrison et al. (2010) for African farmers); such an explanation may be relevant in our case and may be interesting question for future research.

\section{Conclusion}

This paper deals with a fundamental question in experimental economics of preferences towards risk: Are risk preferences stable? Our paper contributes to this research question in several ways. First, we propose a finer characterization of the instability of risk preferences, and a categorization of individuals as regard to the stability (or not) of their preferences towards risk. We observe that the sample is approximately equally split between individuals with stable preferences (42.81\%) and with unstable ones (45.71\%), weak (34.53\%) and strong (11.18\%). In addition, we observe that among individuals with unstable preferences, the weak instability largely dominates the strong one. Second, we identify potential drivers for this instability that may be helpful for future research, in particular the strong impact of undereducation on the probability of instability. Third, we try to clarify what is behind the choice of Gamble 5 in the classic OLS procedure. Our results indicate 
that among those choosing Gamble 5 in the classic procedure, approximately $70 \%$ are risk loving, the others being risk neutral. In this sense, the classic procedure, by putting together individuals who are risk neutral and risk loving, does not allow a precise elicitation of individual preferences towards risk.

At first glance, one limitation of this paper is the difference in payoffs between our two elicitation procedures. However, it seems that this effect is negligiblz, and that our results are driven by the increase in the number of gambles from the classic OLS procedure to the extended one. Another potential limitation is the absence of monetary incentives. However, some papers show that this has no impact on the results (Camerer and Hogarth, 1999; Beattie and Loomes, 1997; Battalio et al., 1990; Wik et al., 2004).

An interesting extension of this research could be a comparison of several existing elicitation procedures on the same sample, i.e. in a between-subject design. Such a comparison would be helpful in understanding the advantages and limits of measurements provided by such procedures, and to have a coherent and relevant use of these measurements to address research questions.

\section{Acknowledgments}

This work was supported by a Labex ARBRE innovative project "Risk Aversion, Livelihoods and Ecosystem Services Provisioning and Deforestation in Multifunctional Landscape (RESEL)". The UMR BETA is supported by a grant overseen by the French National Research Agency (ANR) as part of the "Investissements d'Avenir" program (ANR-11-LABX-0002-01, Lab of Excellence ARBRE).

The University of Auburn is a collaborative partner of this work. Thanks to Pr. Dawoei Zhang for facilitating.

The Center for International Forestry Research-Global Comparative Study (CIFOR-GCS) has contributed to the field work with funding provided by the Norwegian Agency for Development Cooperation (NORAD), grant $n^{o}$ : QZA-12/0882.

\section{References}

L. Anderson and J. Mellor. Are risk preferences stable? Comparing an experimental measure with a validated survey-based measure. Journal of Risk and Uncertainty, 39(2):137-160, 2009. 
K.J. Arrow. Essays in the theory of risk-bearing. Markham Economics Series, 1971.

L. Barseghyan, J. Price, and J.C. Teitelbaum. Are risk preferences stable across contexts ? Evidence from insurance data. American Economic Review, 101(2):591-631, 2011.

R. Battalio, J. Kagel, and K. Jiranyakul. Testing between alternative models of choice under uncertainty: Some initial results. Journal of Risk and Uncertainty, 3(1):2550-, 1990.

J. Beattie and G. Loomes. The impact of incentives upon risky choice experiments. Journal of Risk and Uncertainty, 14:155-168, 1997.

J. Berg, J. Dickhaut, and K. McCabe. Risk preference instability across institutions: A dilemna. Proceedings of the National Academy of Sciences, 201(11):4209-4214, 2005.

E. Biénabe and D. Sautier. The role of small scale producers' organizations to address market access. Proceedings of the International Seminar, 28 February - 1 March 2005, Westminster, London, UK, 2005.

H.P. Binswanger. Attitudes toward risk: Experimental measurement in rural India. American Journal of Agricultural Economics, 62:395-407, 1980.

G. Bocquého, F. Jacquet, and A. Reynaud. Expected utility or prospect theory maximisers? Assessing farmers' risk behaviour from field-experiment data. European Review of Agricultural Economics, 41:135-172, 2014.

D. Bougherara, X. Gassmann, L. Piet, and A. Reynaud. Structural estimation of farmers' risk and ambiguity preferences: A field experiment. European Review of Agricultural Economics, 44(5): 782-808, 2017.

C.F. Camerer and R. Hogarth. The effects of financial incentives in experiments: A review and capital-labor-production framework. Journal of Risk and Uncertainty, 1(19):7-42, 1999.

S. Choi, R. Fisman, D. Gale, and S. Kariv. Consistency and heterogeneity of individual behavior under uncertainty. American Economic Review, 97(5):1921-1938, 2007.

Y. Chuang and L. Schechter. Stability of experimental and survey measures of risk, time, and social preferences: A review and some new results. Journal of Development Economics, 117:151-170, 2015 .

T. Le Cotty, E. Maître d'Hotel, R. Soubeyran, and J. Subervie. Wait and sell: Farmer preferences and grain storage in Burkina Faso. Working Paper LAMETA, 2014.

C. Dave, C.C. Eckel, C.A. Johnson, and C. Rojas. Eliciting risk preferences: When is simple better? Journal of Risk and Uncertainty, 41(3):219-243, 2010.

C. Deck, J. Lee, J. Reyes, and C. Rosen. Measuring risk attitudes controlling for personality traits. Working paper, University of Arkansas, 2008.

C. Deck, J. Lee, J. Reyes, and C. Rosen. Measuring risk aversion on multiple tasks: Can domain specific risk attitudes explain apparently inconsistent behavior ? Working paper, 2010.

C.C. Eckel and P.J. Grossman. Forecasting risk attitudes: An experimental study using actual and forecast gamble choices. Journal of Economic Behavior and Organization, 68(1):1-7, 2008. 
Antonio Filippin and Paolo Crosetto. A reconsideration of gender differences in risk attitudes. Management Science, 62(11):3138-3160, 2016.

U. Gneezy and J. Potters. An experiment on risk taking and evaluation periods. Quarterly Journal of Economics, 112:631-645, 1997.

G.W. Harrison, S.J. Humphrey, and A. Verschoor. Choice under uncertainty: Evidence from Ethiopia, India and Uganda. Economic Journal, 120(543):80-104, 2010.

C.A. Holt and S.K. Laury. Risk aversion and incentive effects. The American Economic Review, 92(5):1644-1655, 2002.

F.E. Kydland and E.C. Prescott. Time to build and aggregate fluctuations. Econometrica, 50: 1345-1370, 1982.

E. Liu. Time to change what to sow: Risk preferences and technology adoption decisions of cotton farmers in China. Review of Economics and Statistics, 95(4):1386-1403, 2013.

J. Ngouhouo Poufoun, J. Abildtrup, D.J. Sonwa, and P. Delacote. The value of endangered forest elephants to local communities in a transboundary conservation landscape. Ecological Economics, 126:70-86, 2016.

A. Reynaud and S. Couture. Stability of risk preference measures: Results from a field experiment on French farmers. Theory and Decision, 73:203-221, 2012.

H. Schildberg-Horisch. Are risk preferences stable ? Journal of Economic Perspectives, 32(2): 135-154, 2018.

M. Wik, T.A. Kebede, O. Bergland, and S.T. Holden. On the measurement of risk aversion from experimental data. Applied Economics, 36(21):2443-2451, 2004. 


\section{A Description of the questionnaire}

The survey is about socioeconomic and ecological analysis of land uses in the Tridom complex. The answers provided are strictly confidential and will be analyzed for the writing of a doctoral thesis. This thesis aims to reflect on a diagram optimal planning that integrates social, economic and also concerns about conservation of biodiversity at the scale of the Tridom landscape.

Please kindly give me some of your precious time to answer the questionnaire. By ensuring the confidentiality of your answers, we thank you in advance for your agreement.

The questionnaire is composed of three parts and 30 pages.

Part 1 is dedicated to the choice determinants of land use and conversion. The first section deals with the socioeconomic characteristics of the household (age, gender, etc.) with 37 questions. The second section is about the autochthony and tribal affiliation (ethnic group, seniority in the village, etc.) with 7 questions. Third section tackles the land ownership and the nature of the land ownership and uses of forest land (non-timber forest product, property right, etc.) with 17 questions. Fourth section questions the conflict, land grabbing, overlapping and superimposition of user rights with 5 questions. Section fifth concerns transportation infrastructure and urbanization (road network, means of transport, etc.) with 4 questions. Section sixth questions the access to some basic services like access to water, electricity, etc. and also deals with housing characteristics. Section seven is interested in the health and education of the household's members while section eight questions the households about food safety. The last section is large and composed with 45 questions about the multifunctionality of the landscape: cultural value, tradition, conservation, spiritual and genetic value of the forest for people.

Part 2 of the questionnaire is dedicated to the measurement of the parameters of risk aversion.

Dear participant, we stop the questionnaire for a short time and we propose to you a little game. More precisely, we propose to you two different tables composed of 5 gambles and 9 gambles respectively. For each table, you have to choose the gamble that you accept to play for given that each gamble is associated to two payoffs having $50 \%$ chance to occur each.

\begin{tabular}{|c|c|c|}
\hline & Payoff 1 & Payoff 2 \\
\hline Gamble 1 & 4 & 4 \\
Gamble 2 & 3 & 6 \\
Gamble 3 & 2 & 8 \\
Gamble 4 & 1 & 10 \\
Gamble 5 & 0 & 12 \\
\hline
\end{tabular}

\begin{tabular}{|c|c|c|}
\hline & Payoff 1 & Payoff 2 \\
\hline Gamble 1 & 100 & 100 \\
Gamble 2 & 80 & 128 \\
Gamble 3 & 60 & 160 \\
Gamble 4 & 40 & 195 \\
Gamble 5 & 30 & 215 \\
Gamble 6 & 20 & 229 \\
Gamble 7 & 18 & 232 \\
Gamble 8 & 10 & 234 \\
Gamble 9 & 3 & 235 \\
\hline
\end{tabular}


Part 3 of the questionnaire is composed with a choice experiment. In this part, it is indicated that forest provides a significant set of economic, social and environmental functions and benefits. However, due to its overuse, these functions may disappear in the future if nothing is done. Therefore, government agencies and NGOs consider the implementation of policies that will ensure the future supply of environmental goods and services. These policies may have an influence on people in your area. This study evaluates your preferences for different policies, knowing that they vary according to different attributes such as the biodiversity, the spiritual and cultural resources area, elephant population, forest landscape, and a potential individual compensation. The rest of the choice experiment is classic. Two blocks composed with 9 cards with different combinations of the attributes are proposed to the households. 